\title{
Bleeding hepaticojejunostomy anastomotic varices successfully treated with Histoacryl injection, using single-balloon enteroscopy
}

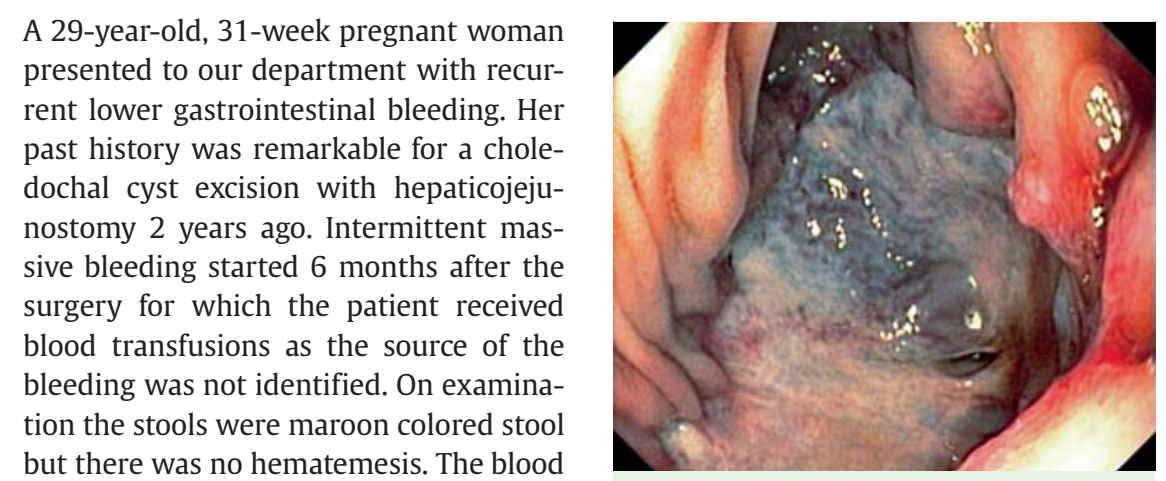
tests were negative for hypercoagulable factors. Esophagogastroduodenoscopy revealed few small esophageal varices and one small gastric varix, without bleeding stigmata, while a colonoscopy was normal. The patient's pregnancy was terminated at 34 weeks because of the recurrent lower gastrointestinal bleeding. Anastomotic varices were suspected to be the source of the bleeding, and thus, single-balloon enteroscopy was carried out. The enteroscopy revealed multiple varices with white and red nipple signs around the hepaticojejunostomy anastomotic site ( Fig. 1). A total of $3 \mathrm{~mL}$ of glue mixture (0.5 mL of $N$-butyl-2-cyanoacrylate [Histoacryl] and $0.8 \mathrm{~mL}$ of Lipiodol) was injected at the varices under fluoroscopic guidance ( Figs. 2, 3). The patient underwent computed tomography (CT) for portal vein evaluation, which showed embolic glue material in liver parenchyma, small portal vein branches, and multiple filling defects in branches of the superior mesenteric vein (SMV) that were hyperdense in the contrast phase, suggestive of acute SMV branch thrombosis. The patient developed moderate abdominal discomfort without elevation of liver enzymes, but the pain disappeared within few days of conservation management. The patient continues to be free from abdominal pain and bleeding, and a 3-month follow-up single-balloon enteroscopy revealed no residual anastomotic varices ( $\bullet$ Fig. 4 ).

Anastomotic varix is an uncommon form of ectopic bleeding varices [1]. In our case, endoscopic treatment with glue injection was the preferred treatment for this type of varices [2,3]. There have been no prior reports of Histoacryl injection using a single-balloon enteroscope. This
Fig. 1 White and red nipple signs of bleeding anastomotic varices.

Fig. 2 Image taken after Histoacryl injection at the varices.

technique makes it relatively easy to diagnose and treat deep small-bowel lesions with minimal complications.

\section{Endoscopy_UCTN_Code_TTT_1AP_2AD}

Competing interests: None

\section{Prachayakul, P. Aswakul, \\ U. Kachintorn}

Department of Internal Medicine, Siriraj

Hospital, Bangkoknoi, Bangkok, Thailand

\section{References}

1 Watanabe N, Toyonaga A, Kojima S et al. Current status of ectopic varices in Japan: Results of a survey by the Japan Society for Portal Hypertension. Hepatol Res 2010; 40: $763-776$

2 Ahmed H, Khalid A, Mohamed A. Updates in the pathogenesis, diagnosis and management of actopic varices. Hepatol Int 2008; 2: $322-334$

3 Deepak K, Sharma B, Sriram P. Endoscopic management of bleeding ectopic varices with histoacryl. HBP Surg 1999; 11: 171 173

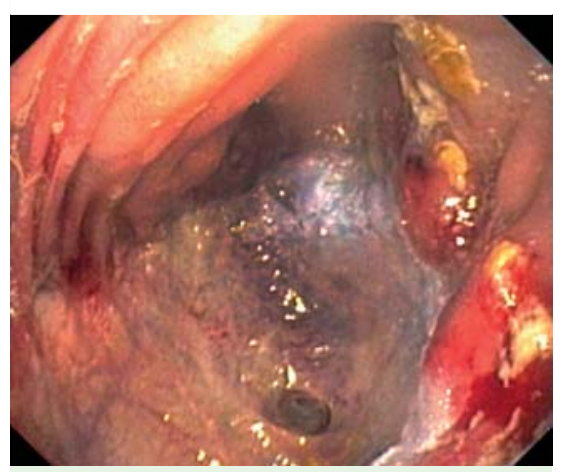

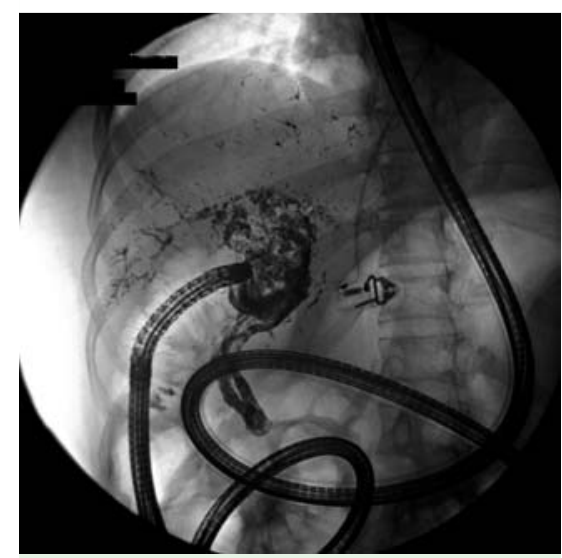

Fig. 3 Computed tomography (CT) scan showed multiple foci of glue material in the portal vein branches.



Fig. 4 The latest enteroscopy, showing no residual varices after treatment.

Bibliography

DOI $10.1055 / \mathrm{s}-0030-1256233$

Endoscopy 2011; 43: E153

(c) Georg Thieme Verlag KG Stuttgart · New York . ISSN 0013-726X

Corresponding author

P. Aswakul

Siriraj Endoscopy Center - Internal Medicine Siriraj Hospital

BangkokNoi

Bangkok

Thailand 10700

Fax: +66-24-299672

asawakul@gmail.com 